\title{
Behaviour of reinforced columns with E_Glass fiber and carbon fiber
}

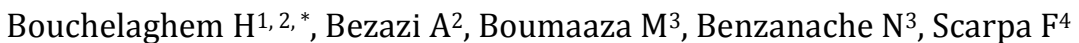

1 Department of Mechanical Engineering, Faculty of Science of Technology, Mentouri Brothers University, Constantine 25000, Algeria.

2 Laboratory of Applied Mechanics of New Materials (LMANM), University 8 May 1945, BP 401 Guelma 24000 , Algeria.

3 Laboratory of Civil and Hydraulic Engineering (LGCH), University 8 May 1945, BP 401 Guelma 24000, Algeria.

4 Department of Aerospace Engineering, University of Bristol, BS8 1TR Bristol, UK.

* Corresponding Author: bouchelaghem h@yahoo.fr

\begin{abstract}
Externally bonded reinforcement using Fiber Reinforced Polymer (FRP) is a good response to the concern represented by the need for rehabilitation of concrete structures. These techniques are more and more attractive because of their fast and low labour costs, very good strength to weight ratio, good fatigue properties, and non-corrosive characteristics of FRP. The present work is an experimental study investigating the mechanical behaviour under a uni-axial loading of short concrete columns reinforced by composite materials. These are constituted of glass fibers GFRP (bidirectional fabric of two surface densities 500 and $300 \mathrm{~g} / \mathrm{m}^{2}$ ), carbon CFRP (unidirectional sheet of density per unit area of $230 \mathrm{~g} / \mathrm{m}^{2}$ ) and polyester and epoxy resin respectively. The investigation aims at demonstrating the effectiveness of FRP reinforcement through highlighting the effect of thickness (FRP number of folds), the nature of the reinforcement (glass, carbon or Hybrid), and the orientation of the fibers. The axial lengths shortening along with the radial expansion are measured using the strain gauges glued to the outer surfaces of the composite jacket via a Wheatstone bridge. These measurements are saved to a PC through an acquisition card. The results obtained clearly show that the columns reinforced with CFRP folds allow an important increase in the compressive rupture stress in comparison with those reinforced with GFRP folds. The gains in compressive strength, in axial and in radial strains of the confined concrete with the different FRPs used are identified and quantified. It has further been demonstrated that the tested columns mechanisms depend strongly on the type of fiber reinforcements.
\end{abstract}

Key words: Concrete columns reinforcement; uni-axial compression; FRP; Structure rehabilitation; Fiber orientations.

\section{Introduction}

The durability of reinforced concrete structures depends on their behavior in relation to the climatic and environmental conditions that exist in the environments in which they are constructed. These structures are often exposed to numerous physico-chemical aggressions which they must satisfy, during their period of use, all the functions for which they were designed.

When they can no longer resist these aggressions, disorders appear in the concrete of these structures. These disorders are generally due to design flaws, poor implementation or accidental causes, but these disorders can be also due to non-compliance with quality standards in manufacturing by certain companies. These behaviors, if not rectified, undermine the durability, resistance and stability of the structures and can lead to their degradation and then their ruin (Ndzana Akongo, 2007).

Fiber-reinforced polymer (FRP) structural composite technology appeared for the first time in the mid-1930s as an experimental boat hull made of glass fiber and polyester resin. From military applications in the 1940s to the manufacturing and industrial sectors in the 1950s, FRP composites have gradually become the preferred alternative to traditional repair techniques. 
Their popularity was mainly due to their excellent strength-to-weight ratio and their superior strength, inherent in climatic conditions and the corrosive effects of salt media (MAPEI, 2015). Numerous research and practical projects have demonstrated the effectiveness of the rehabilitation technique of buildings and structures by bonding FRP elements used as external reinforcement (Lam, 2009; Karbhari, 2009; Karbhari, 2004; Mirmiran, 1997).

An experimental and analytical study carried out by Tamuzs et al. (2007) on the deformability and concrete reinforcement by steel bars, compared with the properties of concrete specimens externally confined by FRP. They carried out experiments to estimate the participation of the steel bars reinforcement and the carbon/epoxy confinement of the concrete cylinders.

The effect of composite confinement architectures (E glass /Vinylester and carbon/epoxy) on the effectiveness of concrete columns reinforcement of the wrapped and then subjected to compression loading was investigated experimentally by Zhang et al. (2000). Moreover, these authors proposed evaluating the efficiency of each individual system by a cost index.

Shehata et al. (2002) carried out 54 tests on short columns to determine the strength and ductility gains of the concrete columns by covering them with carbon FRP sheets. Equations have been proposed to calculate the strength of the confined concrete and its ultimate specific deformation as a function of the lateral confinement stress.

The present work is an experimental investigation carried out on a series of cylindrical columns of concrete subjected to uni-axial compression. Two types of composite material confinement are used (GFRP and CFRP) and six stacks are made (see Table 1).

The aim of this study is to highlight the effectiveness of the reinforcement by FRP through the study of the influence of the envelope FRP staking sequence and the type of reinforcement (glass or carbon fiber) on the confined columns structural behavior. The strength, axial and radial strains gains are evaluated and analyzed, with identification of the failure and damage modes of the reinforced specimens.

Table 1. Specimen's classifications.

\begin{tabular}{|c|c|c|c|}
\hline Description & Stack & Description & Stack \\
\hline \hline Concrete Pilot & not confined & T500 & 3tr_T500 \\
\hline C2 & $\left(0_{2} / 90_{2}\right)$ & H1 & 2tr_H_t500 t300 \\
\hline C4 & $\left(90_{2} / 0_{2}\right)$ & H2 & 2tr_H_t300 t500 \\
\hline & & H3 & 2tr_H_T-Mat \\
\hline
\end{tabular}

\section{Material study and experimental protocol}

\subsection{Concrete columns preparations}

The concrete cylinders specimens having a size of $16 \times 32 \mathrm{~cm}$ are prepared by a series of 50 samples by a company with a concrete plant (GESI-BAT, Algeria), thus obtaining the more or less uniform specimens. After 28 days, the surfaces of the concrete cylindrical specimens are brushed in order to obtain a rough and clean surface.

In other words, the purpose of the surface preparation of the concrete is to remove any surface traces of oil, grease, formwork and other soiling in order to achieve a clean surface able to receive the resin. The cylindrical surfaces ends are ground with a stone to ensure the flatness of the contact surfaces and their perpendicularity to the cylindrical one.

\subsection{FRP external confinement}

The technical adopted in this work for confining the specimens by FRP layers is the direct in-situ stratification technique. Two types of resins are used for two different reinforcements, the first one is a polyester resin used for both types of bi-directional fabrics (T500) and (T300) and the 
Mat (M300) made of glass fibers (T, H1, H2 and H3). However, the second is SIKADUR 330 epoxy resin used for a SIKA WRAP HEX $230 \mathrm{C}$ carbon fiber unidirectional sheet for C2 and C4 confinements (Fig. 1).

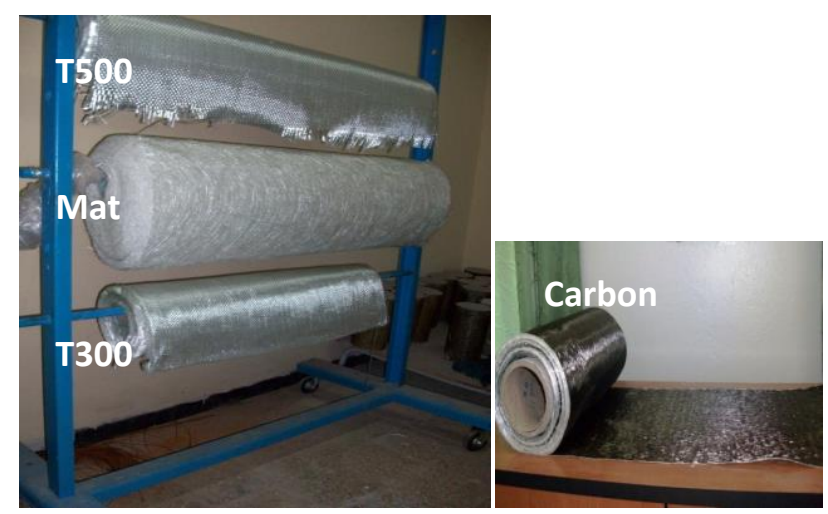

Fig 1. Different types of reinforcements used.

\subsection{Compression test}

In order to evaluate the behaviour of wrapped concrete columns a strain gauges are glued to the center of each specimen vertically and horizontally. These strain gauges measure axial shortening and radial expansion using a Wheatstone bridge. The specimens loading must be carried out without shock and continuously at a constant speed throughout the test.

\subsection{Preparation of the polyester resin}

The polyester resin used consists of three components (the resin, the hardener and the accelerator. Their preparation is easy, the desired quantity of the resin is put into a plastic bowl and then $1.5 \%$ of hardener is added and then mixed until a pink color is obtained, and finally 1 $\%$ of the accelerator is added and mixed again until the mixture becomes dark green, so the resin is ready to be used.

\subsection{Preparation of the epoxy resin}

The epoxy resin SIKADUR 330 consists of two components, resin and hardener (Fig. 2), which must be mixed shortly before application. The proportion by mass of the hardener represents $25 \%$ of the mass of the resin according to the recommendations of the supplier. The mixing was carried out for about three minutes until complete disappearance of the color streaks and obtaining a homogeneous mixture.

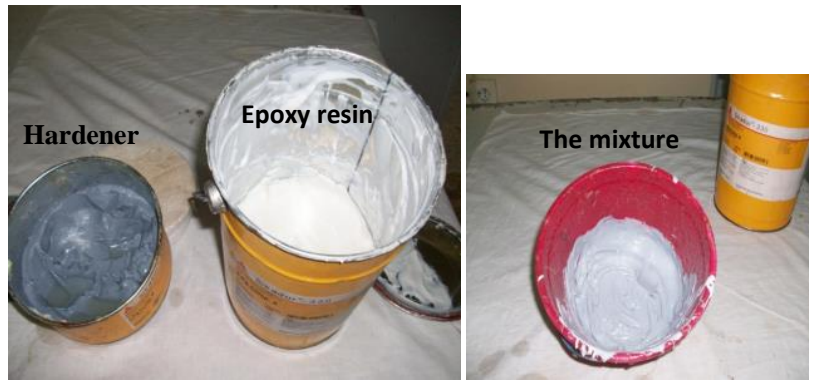

Fig 2. Components of the epoxy resin used.

\subsection{Specimens FRP wrapping}

Two types of reinforcement are used, Glass fiber reinforced polymer (GFRP), and CFRP (Carbon fiber reinforced polymer). The fabric reinforcing bands (glass or carbon fibers) were measured 
and then cut with a cutter and a metal ruler. The length of the confinement bands fold correspond to the perimeter (for a layer) or to $\mathrm{n}$ times for $\mathrm{n}$ layers. In addition, the outer layer is extended (overlapping in the longitudinal direction of the fibers) in order to ensure a $1 / 4$ perimeter overlap which allows the full strength of the fibers to be developed without slipping or peeling the composite layer (Fig. 3).

The main advantage of dry fabric reinforcement is easy handling on site, without any heavy equipment to move. This technique allows in particular a perfect follow-up of the shape of the reinforced structure.

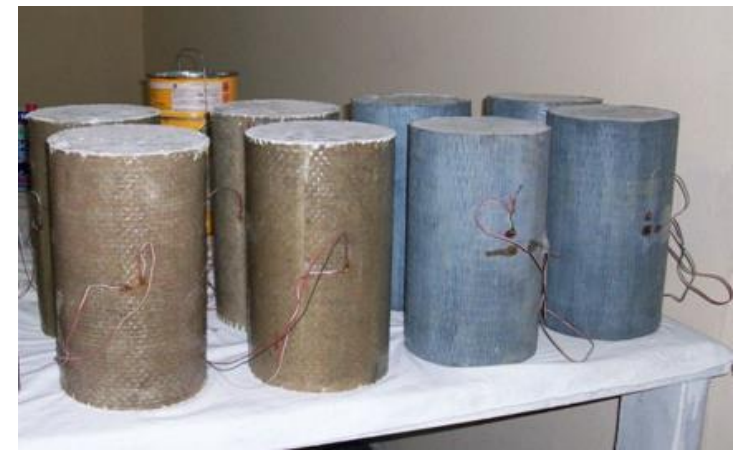

Fig 3. Column wrapped models.

\subsection{Testing machine and instruments}

The simple compression tests were carried out with a constant loading speed until rupture in accordance with ASTM C39 / C39M-9a, using a hydraulic press with a capacity of $3000 \mathrm{kN}$ "CONTROLS Model 50-C55G2/" equipped with a DIGIMAX PLUS (Fig. 4). The data are transmitted to the automatic acquisition system via an interface. The tests are carried out within the Laboratory of Civil and Hydraulic Engineering (LGCH) of the University 08 May 1945 of Guelma.

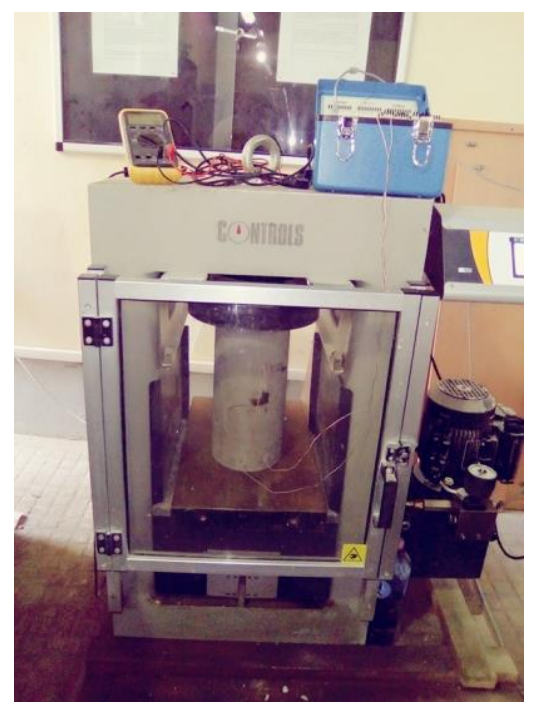

Fig 4. Testing machine and Wheatstone bridge.

\section{Results and discussions}

\subsection{GFRP wrapped specimens effects}

The experimental tests results are graphically presented in the form of stress/strain curves in FIG. 5. The curves of the stresses are plotted as a function of the axial and radial strains in the 
same reference frame. Typically, these curves have an initial slope which follows that of the control concrete up to a point of inflection, followed by a zone of great plastic deformation. While, the second slope in the plastic area is much lower than the first. This characterizes the contribution of the reinforcement which depends on the orientation and the nature of the fibers of the composite envelope.

The curves show the effect of the stacking sequence on the structural behavior of the confined specimens compared to that of the control concrete subjected to compression loading.

The analysis of the results obtained shows that the specimens wrapped by T500 or H3 gives an increase of 65 and $60 \%$ in the resistance respectively. Whereas, the hybrids $\mathrm{H} 1$ and $\mathrm{H} 2$ having the ultimate stresses equal to 39 and $37 \mathrm{MPa}$ respectively, thus allowing an improvements of 43 and $41 \%$ respectively (Table 2 ).

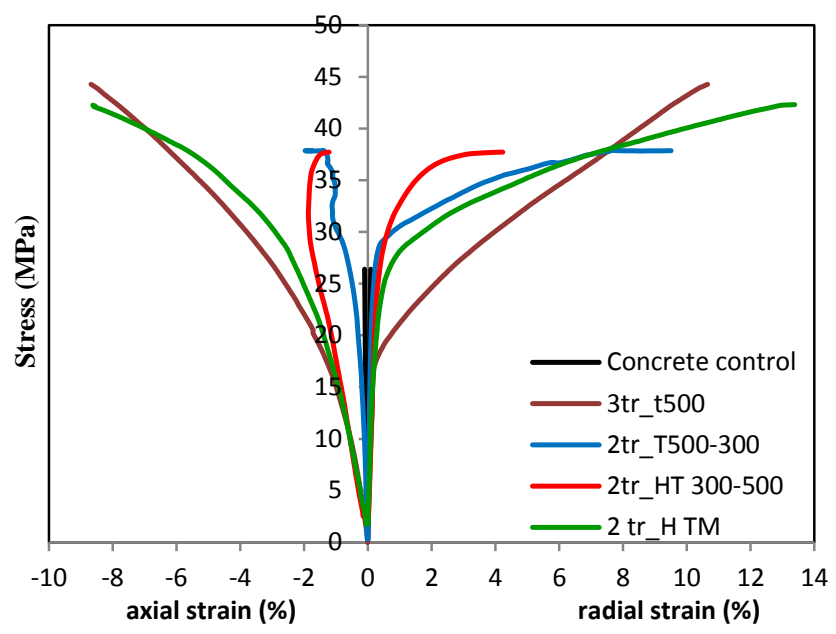

Fig 5. Stress/strain behavior of stacks in GFRP.

\subsection{CFRP wrapped specimens effects}

The mechanical behavior of columns confined by envelopes constituted by four CFRP plies having a staking sequence of $\mathrm{C} 2\left(0_{2} / 90_{2}\right)$ and $\mathrm{C} 4\left(90_{2} / 0_{2}\right)$ are illustrated in Fig. 6 . The confined columns are subjected to repetitive uniaxial compression loading until their final failure (i.e. until obtaining the load failure lower than the one of the control concrete).

The stress/strain curves of specimens wrapped by CFRP $\left(0_{2} / 90_{2}\right)$ and $\left(90_{2} / 0_{2}\right)$ respectively show that the $\mathrm{C} 2$ resists up to seven loads whereas, $\mathrm{C} 4$ resists only two loads (Figs. 6 and 7). The comparison of $\mathrm{C} 2$ and $\mathrm{C} 4$ for the first two loads showed bilinear behavior (Fig. 7). C2 lead to have the best ultimate load capacity at the second loading where the stress reached $61.41 \mathrm{MPa}$, i.e. an increase of $136 \%$ compared to the control concrete. However, C4 present the best behavior from the point of view of repetitive loading with a maximum stress of $49.9 \mathrm{MPa}$ obtained during the third loading to an increase of $89 \%$.

The analysis of the $\mathrm{C} 4$ strains for the two loadings showed that the obtained axial and radial strains are practically identical and increase by (356\%) and (1252\%) respectively compared to the ones obtained for the control concrete. However, for $\mathrm{C} 2$, the axial and radial strains gains obtained are lower than those found for $\mathrm{C} 4$ and the both are equal to $23 \%$ (Table 2). In general, the two stacking sequences of the CFRP composite used for the confinement of the columns show a high performance compared to the GFRP composite studied. This is in good agreement with previous works of Bouchelaghem et al. $(2011 \mathrm{a}, \mathrm{b})$. 


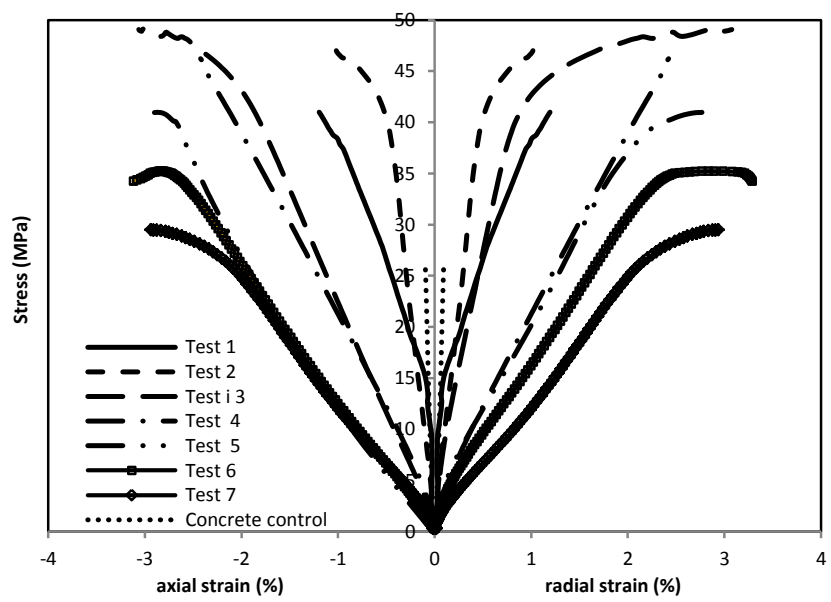

Fig 6. Stress/strain behavior of the repeated loading of the column wrapped by $\mathrm{C} 2\left(\mathrm{O}_{2} / \mathrm{90}_{2}\right)$.

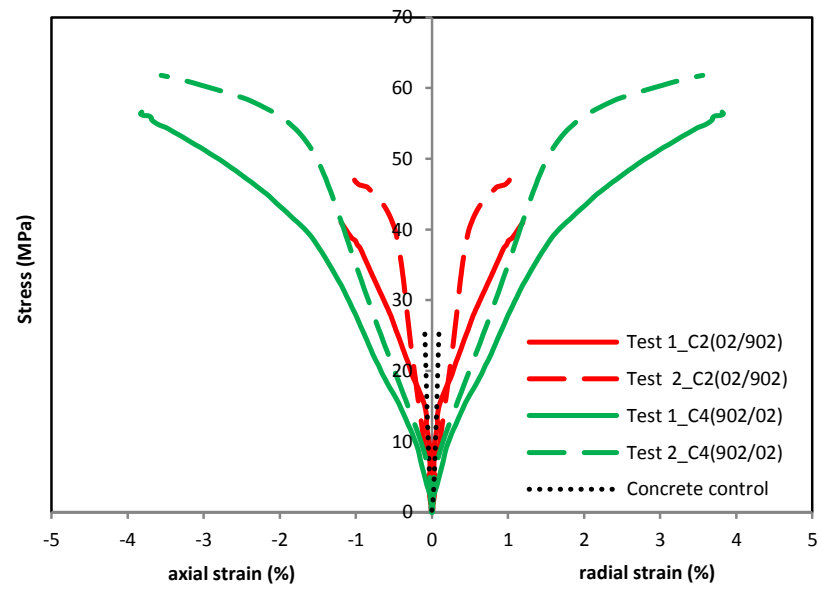

Fig 7. Comparison between the stress/strain behavior, first and second loading, of $\mathrm{C} 2\left(\mathrm{O}_{2} / \mathrm{90}_{2}\right)$ and $\mathrm{C4}$ $\left(90_{2} / 0_{2}\right)$.

Table 2. Mean values of the test results of confined columns..

\begin{tabular}{|c|c|c|c|c|c|c|c|c|}
\hline Config.de confin. & $F_{\max }(k N)$ & $f_{c}^{\prime}(M P a)$ & $\begin{array}{c}f_{c c}^{\prime} \\
(M P a)\end{array}$ & $f_{c c}^{\prime} / f_{c o}^{\prime}$ & $\varepsilon_{c c} \%$ & $\varepsilon_{c c} / \varepsilon_{c o}$ & $\varepsilon_{r, \text { rup }} \%$ & $\begin{array}{c}\mathcal{E}_{r,} \\
\text { rup } / \varepsilon_{r o}\end{array}$ \\
\hline Concrete control & 530.45 & \multirow{7}{*}{26.39} & 26.39 & 1.00 & 0.98 & 1.00 & 0.92 & 1.00 \\
\hline $\mathrm{T}$ & 909.44 & & 43.74 & 1.65 & 8.42 & 8.59 & 10.65 & 11.57 \\
\hline $\mathrm{H} 1$ & 759.27 & & 37.83 & 1.43 & 1.74 & 1.77 & 8.75 & 9.51 \\
\hline $\mathrm{H} 2$ & 757.90 & & 37.41 & 1.41 & 1.84 & 1.87 & 5.43 & 5.90 \\
\hline H3 & 858.72 & & 42.30 & 1.60 & 8.21 & 8.37 & 13.39 & 14.55 \\
\hline $\mathrm{C} 2$ & 829.50 & & 41.66 & 1.57 & 1.15 & 1.23 & 1.21 & 1.23 \\
\hline $\mathrm{C} 4$ & 1137.77 & & 56.35 & 2.13 & 3.71 & 3.78 & 3.83 & 4.16 \\
\hline
\end{tabular}

$\mathrm{f}_{\text {cc }}$ : axial compressive strength of confined concrete; $\varepsilon_{c c}, \varepsilon r$,rup: axial and radial deformations respectively. 


\subsection{Failure modes of the columns confined by CFRP and GFRP}

The Fig. 8 shows the fractures of the specimens confined by GFRP and CFRP. In the case of GFRP the damage is initiated by local delaminations between the FRP envelope and the concrete which results in a change of color noted on the photos (the most damaged areas change its color and become white due to the delamination). Then, a crack growth is obtained in the directions of the fibers (horizontal and vertical), whereas the total failure of the composite jacket is obtained by a dominate crack which occur in the vertical direction (i.e. in the direction of loading).

The damage are located in the lower parts of the columns confined by the $\mathrm{C} 4\left(90_{2} / 0_{2}\right)$ envelopes having the layer oriented at 0 in contact with the concrete. However, the cracks and breaks observed are located in the upper parts for the columns confined by $\mathrm{C} 2\left(0_{2} / 90_{2}\right)$ envelopes having the layer oriented at 90 in contact with the concrete.
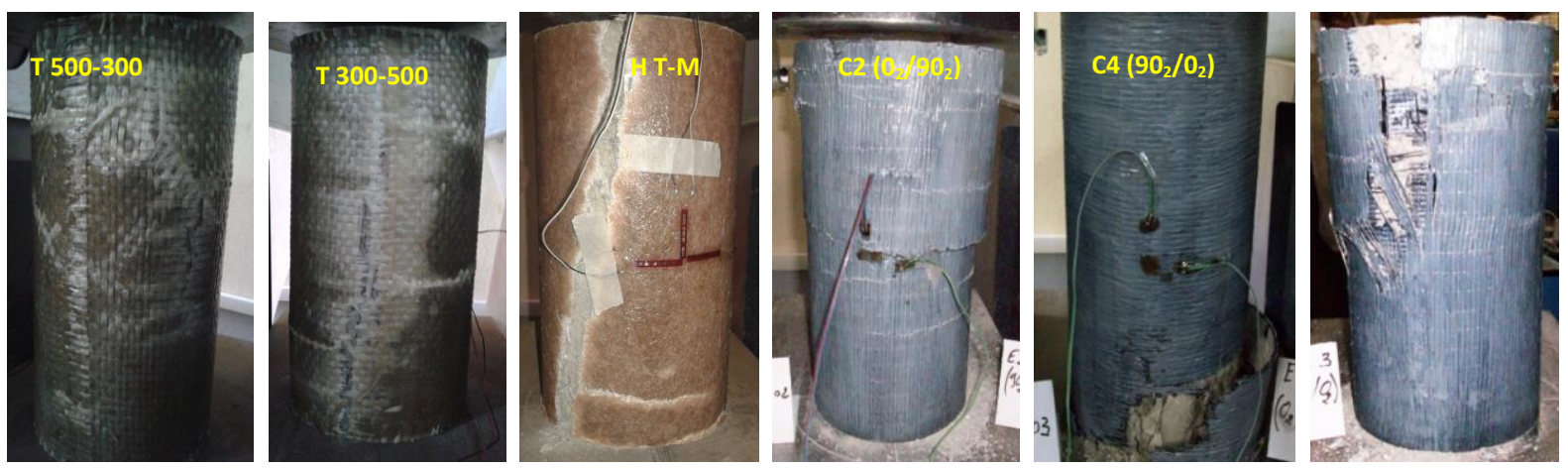

Fig 8. Failure facies of the columns confined by the envelopes: a) GFRP T500, H1, H2, H3 and control concrete, b) CFRP $\left(0_{2} / 90_{2}\right)$ and $\left(90_{2} / 0_{2}\right)$.

Columns confined by FRPC envelopes are generally characterized by fragile fracture obtained by explosion or brutal of the composite jacket; as is the case with stacking C4 $\left(90_{2} / 0_{2}\right)$ and $\left(0_{2} / 90_{2}\right)$. These phenomena are caused not only by the high strength of the carbon fibers but also by the rigid confinement due to a large number of folds (four plies) and their orientations. Indeed, the fibres oriented at 0 are subjected to the tensile loading due to swelling of the test specimens during loading, while, the one oriented at 90 are loaded at compression.

The use of GFRP composite materials in the repair and/or reinforcement of concrete structural elements (short columns), subjected to uni-axial compression have an acceptable efficiency in strength, axial and radial strains compared to those confined by CFRP. The Fig. 9 clarifies the effectiveness of this technique and shows well the gains and increases obtained for each system.

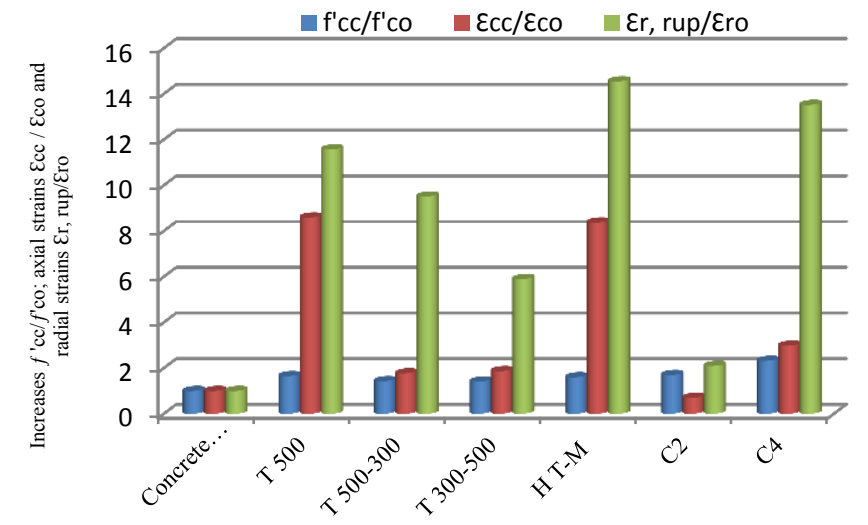

Fig. 9. Effectiveness of concrete reinforcement by FRP in terms of stresses axial and radial strains. 


\section{Conclusions}

According to the study of externally wrapped concrete columns subjected to uni-axial compression loading the main conclusions are:

- $\quad$ The columns confined by the GFRP and CFRP composite subjected to a repetitive loadings, showed a more rigid compared to the concrete control;

- $\quad$ The best gains in axial and radial strains are equal to $356 \%$ and $1252 \%$ respectively obtained for the column wrapped by $\mathrm{C} 4\left(90_{2} / 0_{2}\right)$. While, for $\mathrm{C} 2\left(0_{2} / 90_{2}\right)$, the axial and radial strains gains obtained are for the both only $23 \%$;

- $\quad$ The study of the columns confined by the hybrids adopted H1, H2 and H3 showed that their stress/strain behaviors follow the first folds i.e. the layers in direct contact with the concrete; however, their failure mode damage types follow the one of the external folds;

- $\quad$ Fractures of columns confined by CFRPs are marked by a brutal rupture of carbon fibers.

\section{References}

Bouchelaghem, H., Bezazi, A., \& Scarpa, F. (2011). Compressive behaviour of concrete cylindrical FRPconfined columns subjected to a new sequential loading technique, composite parte B, 42, 19871993.

Bouchelaghem, H., Bezazi, A., \& Scarpa, F. (2011). Strength of concrete columns externally wrapped with composites under compressive static loading, Reinforced Plastics and Composites, 30 (19), 16711688.

Karbhari, V. M. (2004). Fiber reinforced composite bridge systems-transition from the laboratory to the field, Composite Structures, 66, 5-16.

Karbhari, V. M., \& Ghosh, K. (2009). Comparative durability evaluation of ambient temperature cured externally bonded CFRP and GFRP composite systems for repair of bridges, Composite: Part A, 40, 1353-1363.

Lam, L., \& Teng, J.G. (2003). Design-oriented stress-strain model for FRP-confined concrete, Construction and Building Materials, 17, 471-489.

MAPEI (2015). Corporation, Polymères renforcés de fibres (PRF), Siège social des Amériques.

Mirmiran, A., \& Shahawy M. (1997). Dilation characteristics of confined concrete, mechanics of cohesive frictional Materials, 2, 237-249.

Ndzana Akongo, \& Tchoumi, S. (2007). Réhabilitation des ouvrages en béton armé dégradés par la corrosion des armatures, Université de Douala.

Shehata, L A. E. M., Carneiro, L. A. V., \& Shehata, L. C. D. (2002). Strength of short concrete columns confined with CFRP sheets, Materials and Structures, 35, 50-58.

Tamuzs, V., Valdmanis, V., Gylltoft, K., \& Tepfers, R., (2007). Behavior of CFRP-confined concrete cylinders with a compressive steel reinforcement, Mechanics of Composite Materials 43 (3).

Zhang, S. L., Mai, Ye Y.W. (2000). A Study on Polymer Composite Strengthening Systems for Concrete Columns, Applied Composite Materials, 7, 125-138. 